\title{
An Analysis of China's International Competitiveness in Competitive Sports Industry by Means of Mathematical Modeling
}

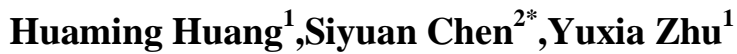 \\ ${ }^{1}$ Sports Culture Research Base of Nanjing University of Information Science \& Technology, Nanjing \\ 210044, China \\ ${ }^{2}$ PE Teachers' Office, Nanjing University Jinling College, Nanjing 210089, China \\ *Corresponding Author.
}

\begin{abstract}
China has joined the world's front rank of competitive sports, with remarkable performance in the Summer Olympic Games in particular. But there is no denying that other events and non-Olympic events have been neglected when emphasis has been put on the Olympic Gold Medal Winning Program. This paper makes a statistical analysis of China's international competitiveness in competitive sports industry by means of mathematical statistics, so as to analyze the deficiencies in China's development in competitive sports industry on the basis of statistical results. This study suggests that although China's international competitiveness in competitive sports is improving rapidly, the gap with the USA remains wide; secondly, China's development in competitive sports is seriously uneven, which is mainly reflected in the development of summer and winter sports; but in the current situation, there are very favorable opportunities for China's development in competitive sports, namely, opportunities in the policy environment, opportunities in the climate for hosting events and opportunities in the transition of household consumption.
\end{abstract}

Keywords: China, Competitive sports, industry, International competitiveness, Opportunities, Challenges

\section{Introduction}

At present, various countries around the world are paying more and more attention to competitive sports, and competition is getting increasingly fierce. In competitive sports, the biggest feature is competition, and the purpose is to win, so competitiveness becomes an important factor affecting the outcome ${ }^{[1]}$. China has joined the front rank of world competitive sports, with remarkable performance in the Summer Olympic Games in particular. The purpose of this paper is to analyze China's international competitiveness in competitive sports and find the deficiencies, so as to provide a data-driven basis for formulating China's competitive sports development strategies.

\section{Mathematical Modeling}

This paper takes a national competitive sports competitiveness index as the assessment tool. In order to reflect a country's overall strength in competitive sports and give consideration to the spirit of humanism, this paper uses the results in five world-class comprehensive sports events as indicators of a country's competitiveness in competitive sports. The five events are the Summer Olympic Games, Winter Olympic Games, Summer Paralympic Games, Winter Paralympic Games and World Games. The specific framework is as follows:

$$
I C=F(S O, S G, W G, W O, W P)
$$

IC represents a country's international competitiveness in competitive sports; SO represents a country's competitiveness in the Summer Olympic Games; SG represents a country's competitiveness in the Summer Paralympic Games; WG represents a country's competitiveness in the World Games; WO represents a country's competitiveness in the Winter Olympic Games; WP represents a country's competitiveness in the Winter

ISSN: 0010-8189

(C) CONVERTER 2021

Www.converter-magazine.info 
Paralympic Games. The statistical indicators are a country's results in the five events during each four-year interval between two Summer Olympic Games. A country's competitiveness is the weighted sum of the numbers of gold, silver and bronze medals won in the five events.

\section{Data Collection and Weighting Methods}

3.1 Data collection

All the data used in this paper are results of the summer and Winter Olympic Games, summer and Winter Paralympic Games and World Games during 1984-2018 published on the official websites of the International Olympic Committee, International Paralympic Committee and International World Games Association.

\subsection{Weighting methods}

3.2.1 Geometric progression

Geometric progression is adopted in weighting gold, silver and bronze medals. The radio of gold medal to silver medal to bronze medal weight ratio is $R^{2}: R: 1, \mathrm{R}=2$. The best thing about this method is that the weight on any rank is greater than the sum of weight on all lower ranks. The specific weight coefficients are shown in Table 1 .

Table 1 Medal weight coefficients

\begin{tabular}{|c|c|c|}
\hline Weighting method & Indicator & Weight \\
\hline \multirow{3}{*}{ Geometric progression } & Gold medal & 0.5714 \\
\cline { 2 - 3 } & Silver medal & 0.2857 \\
\cline { 2 - 3 } & Bronze medal & 0.1429 \\
\hline
\end{tabular}

\subsubsection{Mean value}

To avoid the influence of subjective factors, for example, different countries attach different importance to different events, mean value is adopted in weighting different events, i.e. the weight coefficients of different events are obtained by calculating the mean of the number of participating countries and the number of athletes in each event. The results retain four decimal places and are as follows (Table 2):

Table 2 Event weight coefficients

\begin{tabular}{|c|c|c|c|c|c|}
\hline Indicator & $\begin{array}{c}\text { Summer Olympic } \\
\text { Games }\end{array}$ & $\begin{array}{c}\text { Summer Paralympic } \\
\text { Games }\end{array}$ & $\begin{array}{c}\text { World } \\
\text { Games }\end{array}$ & $\begin{array}{c}\text { Winter Olympic } \\
\text { Games }\end{array}$ & $\begin{array}{c}\text { Winter Paralympic } \\
\text { Games }\end{array}$ \\
\hline Weight & 0.4679 & 0.208 & 0.1405 & 0.1349 & 0.0487 \\
\hline
\end{tabular}

\section{Results and Analysis}

The evolution of China's international competitiveness in competitive sports during 1984-2018 can be divided into two stages. The first was a stage of rapid development from 1984 to 2008; the second was a relatively flat and slightly declining stage from 2012 to 2018 (Figure 1). Relatively speaking, China is a latecomer in competitive sports. As a result, China's competitiveness in competitive sports was not very strong at the beginning. However, with a large population and a nationwide competitive sports management system, China showed significant momentum from the beginning. The competitiveness index shows that China's competitiveness in competitive sports declined after it peaked in 2008 and experienced a huge drop from 0.7108 in 2012 to 0.5406 in 2016 . The biggest reason is that the competitiveness in the Summer Olympic Games fell sharply. Though China still ranked among the top three, the gap with the top medal winner the USA gradually widened in both the number of gold medals and the total number of medals.

ISSN: 0010-8189 


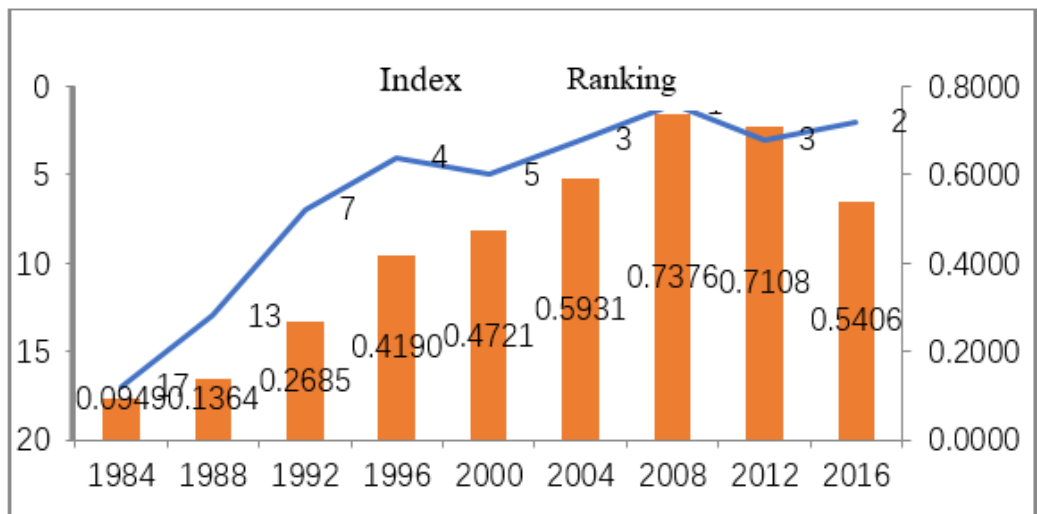

Fig 1: China's international competitiveness index and ranking in competitive sports during 1984-2016

4.1 China's competitiveness in the Summer Olympic Games: China joined the top three but gradually lost competitiveness

China's results improved as a whole after taking part in the Summer Olympic Games for the first time in 1984. But there were two slides, respectively the defeat in the Seoul Summer Olympic Games in 1988 and the decline after 2008. The first slide occurred between 1984 and 1988. China's gold medal tally at the Summer Olympic Games dropped sharply. This was related not only to China's strategy for preparing for the Olympics, but also to the pressure put by the whole country on the athletes to win gold medals, and more to the participation of the former Soviet Union, the former East Germany and other countries (the 1984 Olympics was boycotted by those sporting powers). 2008 was the peak of China's competitive sports development after the founding of the People's Republic of China. In the following decade, China's competitive sports began to decline for the second time, which was shown in the London Olympic Games and the Rio Olympic Games. There were two reasons. One reason was that China's successful hosting of the 2008 Olympics and victory of topping the gold medal tally unleashed a burst of national pride, and the value orientation on using the gold medal tally in the Summer Olympic Games to prove national power and strength gradually faded gradually. The other reason was that China's sports management system was at a critical moment of reform, and the transition from state-run competitive sports to joint operation between the state and society brought about the decline in dominant indicators of competitive sports. It will take time to get rid of the dependence on the paths formed by the "nationwide competitive sports management system" one by one.

\subsection{China's competitiveness in the Summer Paralympic Games: China won the top place and held a safe lead}

According to data analysis, China's strong competitiveness in the Summer Paralympic Games is mainly enabled by China's huge disabled population base, the government's emphasis on disabled sports and China's rapid economic growth. According to official statistics in 2010, the total number of disabled people in China was 85.02 million, including 12.63 million with visual disability, 20.54 million with hearing disability, 1.3 million with speech disability, 24.72 million with extremity disability, 5.68 million with intellectual disability, 6.29 million with mental disability and 13.86 million with multiple disabilities; among them, 59.84 million were moderately or mildly disabled, and 25.18 million were severely disabled. ${ }^{[2]}$ Such a large disabled population base provided a substantial foundation for selecting disabled athletes. Moreover, the Chinese government's attention to disabled sports was another guarantee of China's excellent performance in the Summer Paralympic Games.

4.3 China's competitiveness in the World Games: China lagged far behind other sporting powers as a whole

China's competitiveness in the World Games presented an M-shaped curve (Figure 2). The first ascent was from 1989 to 1997, and the second ascent was from 2005 to 2009. As a whole, it was on an upward curve.

ISSN: 0010-8189

(C) CONVERTER 2021

www.converter-magazine.info 




Fig 2: China's competitiveness index and ranking in the World Games during 1989-2017

This shows that China's competitiveness in the World Games still was not strong yet, especially compared with sporting powers such as the USA, Russia and Germany. Compared with sporting powers with strong overall strength and sporting powers with competitiveness in the World Games, China still faces many challenges and has a long way to go in the World Games.

4.4 China's competitiveness in the Winter Olympic Games: China is backward as a whole, but enjoys a large space for development

China's "Olympic Strategy" for developing competitive sports aims at the Summer Olympic Games and the Winter Olympic Games.However, for a long time, China's Olympic Strategy put more emphasis on the Summer Olympic Games, while the overall level and participation in the Winter Olympic Games remained relatively low and incomplete. China's competitiveness was on a slow upward curve as a whole after taking part in the $13^{\text {th }}$ Winter Olympic Games for the first time in 1980. But statistics show that China's competitiveness in the Winter Olympic Games fluctuated greatly and remained at a middle or low level. China's results in the Winter Olympic Games show that China's competitiveness in the Winter Olympic Games lagged behind European countries for a long time. It wasn't until 2002 that China won the first gold medal at the Winter Olympic Games. China's competitiveness index and ranking in the Winter Olympic Games show a slow upward fluctuating growth trajectory in the past over 30 years. During the first ascent between 1992 and 1998, China's competitiveness index rose from 0.0876 to 0.2032 , which was followed by a brief slide to 0.1829 . Then there was another ascent until it peaked at 0.2861 in 2010, which was followed by a continuous slide through 2014 until the competitiveness index dropped to 0.1892 in 2018. The competitiveness index shows that China's competitiveness in the Winter Olympic Games was weak all the time, and the gap with Russia, Italy, Norway and other European countries strong in the Winter Olympic Games never narrowed.

4.5 China's competitiveness in the Winter Paralympic Games: China leaped from 0 to 1 and shows enormous potential

From the Salt Lake City Winter Paralympic Gamesin 2002 to the PyeongChang Winter Paralympic Games in 2018, China participated in the Winter Paralympic Games five times in total. In the first four times, China didn't win any medals. In the Winter Paralympic Games in 2018, the Chinese team beat the Canadian team by 4:3 in the semifinals of wheelchair curling and advanced to the finals. After nine hard matches in the finals, the Chinese team beat theNorwegian team in overtime by 6:5 and won China's first gold medal in the Winter Paralympic Games. It was the first gold medal and the first medal taken by the Chinese team in the Winter Paralympic Games. China staggered for nearly two decades in the Winter Paralympic Games. The number of athletes grew from four in 2002 to 26 in 2018. In the first few times, China didn't win any medals, but the Chinese team grew stronger and stronger and competed in more and more sports, which shows that China's competitiveness in the Winter Paralympic Games was improving gradually (Figure 3). In the future development, through the selection of athletes and the perfection of the training system, China's competitiveness in the Winter Paralympic Games is bound to be further improved. But because of our weak foundation, there must be a long way to go before we can compete as a sporting powers with other sporting powers in the Winter Paralympic Games.

ISSN: 0010-8189

(C) CONVERTER 2021

www.converter-magazine.info 


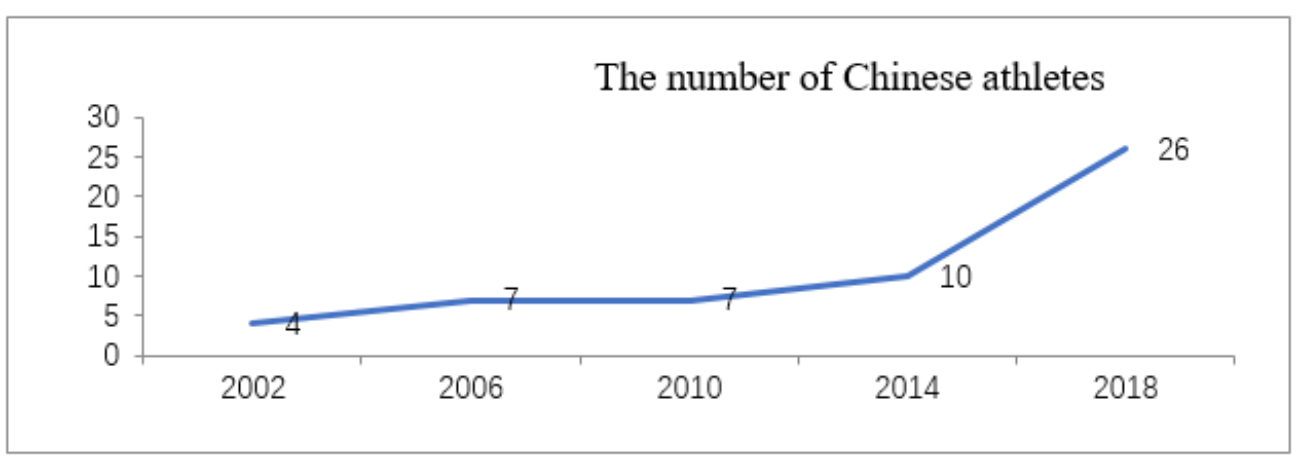

Fig 3: The number of Chinese athletes in the Winter Paralympic Games

\section{Opportunities and Challenges}

\subsection{Opportunities}

\subsubsection{Opportunities in the policy environment}

"Outline of Olympic Gold Medal Winning Program 2011-2020" points out that: "we shall stick to and improve the nationwide competitive sports management system, continue to implement the Olympic Strategy, continue to make outstanding achievements in the Olympic Games and other international events, to win honor for the country." [3] This indicates that China will adhere to the nationwide competitive sports management system in a certain period of time and develop competitive sports with the joint efforts of the whole country. Since the Olympic Gold Medal Winning Program was launched, the development of competitive sports in China has been centered on the Olympic Games, highlighting the strategy of ensuring advantageous sports and developing latent advantageous sports. The most obvious results are the number of gold medals won and medal contribution rate in the traditional six advantageous sports. For example, at the 2008 Beijing Olympic Games, the medal contribution rate of the traditional six advantageous sports was as high as $62 \%$. Therefore, by sticking to the nationwide competitive sports management system and continuing to implement the Olympic Gold Medal Winning Program, China creates a very good policy environment for the development of competitive sports, and no sharp decline in performance will occur due to the market-oriented reform.

\subsubsection{Opportunities in the climate for hosting events}

The hosting of international events is of great significance to the improvement of a country's competitive sports. It's not just reflected in the home advantages during the events ${ }^{[4]}$ but also reflected in the amount of investment a country makes in competitive sports during the events.To a great extent, it can encourage more people to participate in the training for sports events, which is undoubtedly very important for the rapid development of various sports. China obviously lags behind traditional sporting powers in the development of winter sports. Therefore, China's hosting of the Winter Olympic Games in 2022 will create a prime opportunity period for China to vigorously develop winter sports, which will greatly boost the rapid development of snow and ice sports in China.

\subsubsection{Opportunities in the transition of consumption}

Sports are becoming more and more important. Over time, more and more people will engage in active sports consumption. ${ }^{[5]}$ In countries with a developed sports industry, the value added in the sports industry accounts for about $1 \%-3 \%$ of their GDP. ${ }^{[6]}$ China has a huge population. In 2008, China's per capita GDP reached $\$ 3,000$. ${ }^{[7]}$ Such an economic environment and large demand will certainly facilitate the development of competitive sports. More and more people will have more demand for competitive sports culture, which will boost the training of athletes and reserve athletes, as well as the development of highly entertaining and commercial sports. At the same time, the improvement of economic level and consumption level will also broaden the social channels for producing excellent reserve athletes in competitive sports. Therefore, such a transition of consumption is the best

ISSN: 0010-8189 
time for China to steadily develop traditional advantageous sports, and boost the development of non-advantageous, commercial and entertaining sports. It is also the best opportunity period for China to surpass other countries in competitive sports.

\subsection{Challenges}

5.2.1 The weak mass sports foundation for competitive sports

China is now in a transition of consumption, but there is still a big gap between China and developed countries in Europe and America in terms of the number of participants in competitive sports, the scale and level of people's sports-related consumption, and the sports consumption mentality. For example, in terms of participants in competitive sports, China's population is far larger than that of all sporting powers, but the number of people participating in sports or competitive sports may not be as large as that in European or American sporting powers. According to statistics, in $1995,20.10 \%$ and $14.40 \%$ of the US population participated in moderate and high-intensity sports respectively, while the figures were only $7.74 \%$ and $8.44 \%$ in China, ${ }^{[8]}$ far below the USA. Although China has a large sports population base, its contribution to the development of competitive sports is obviously low in the transition from mass sports to competitive sports. This also makes it more difficult to train competitive sports athletes based on mass sports. From a macro point of view, the brilliant achievements of European or American sporting powers in competitive sports are derived from their huge sports populations generated by their powerful mass sports. The mass sports foundation in China is still relatively weak. Therefore, expanding the sports population and improving the sports skill level of the masses is a big challenge for China in developing competitive sports.

\subsubsection{The challenge in shifting focus to different sports}

Every country in the world has a different event structure in the development of competitive sports and every country has basically formed their own advantageous sports on the basis of traditional sports. For example, for event development in the most influential Summer Olympic Games, the USA has laid emphasis on the effect of intensification in major sports and the effect of market-oriented transition in team sports, so its event structure is characterized by highly market-oriented, intensive, comprehensive and coordinated development. ${ }^{[9]}$ China focuses on the factor-driven effect and cumulative effect in advantageous sports, so China's event structure is characterized by clear priorities, comprehensive investment, factor driven development. ${ }^{[10]}$ China has always adopted a government-run sports management model. The government can determine the sports to develop and the strategy for developing competitive sports to a large extent through regulation, resource allocation and capital investment. Therefore, it is easier for China to develop latent advantageous sports. The nationwide competitive sports management system makes it easier to pay more attention to the development of nontraditional advantageous sports. However, China's long-term implementation of the nationwide competitive sports management system has caused many practical problems in shifting focus to different sports. The first problem is the athlete reserve. China's long-term Olympic goal is the number of gold medals and social recognition of sports is not considered. That leads to what the academic circles call China's Olympic strategy of "soft gold medal" sports for developing competitive sports. Due to our single-minded pursuit of "gold medals" in developing competitive sports, the reserve of excellent athletes in traditional advantageous sports is obviously bigger than that in non-traditional advantageous sports. In expanding sports, the lack of elite athletes will limit the development of non-advantageous sports. It will take time and investment to train athletes gradually. The second problem is the supply of public sports services. If the development of a sporting event relies solely on the organizations established by the government, it will lead to dedicated resource allocation and specified resource receivers, resulting in the lack of a solid guarantee of human resources. In the short term, the performance in competitive sports can be improved rapidly, but it is difficult to achieve sustainable development. A solid guarantee of human resources requires a relatively abundant supply of public sports services, such as venues and facilities, etc. Only with sufficient sports venues, facilities and promotion organizations, can we finally form a competitive high-level athletic event. Therefore, focus shifting to different sports is another major challenge for the development of competitive sports in China.

ISSN: 0010-8189

(C) CONVERTER 2021

www.converter-magazine.info 


\section{Conclusion}

China's international competitiveness in competitive sports is already in the front rank, and the gap with the USA, which ranks first, is gradually narrowing. But there is no denying that there are serious imbalances in China's competitive sports development, no matter the imbalance in development between the summer and Winter Olympic Games or the imbalance in development between competitive sports and mass sports. The development of winter sports in particular is seriously lagging behind. It is a major factor that affects China's overall strength in competitive sports. Therefore, considering the current situation, basic characteristics and future development trend of China's competitive sports in international competition, this paper suggests that the development of competitive sports in China should first eliminate the imbalance between summer and winter sports. Only by gradually enhancing the competitiveness in different large-scale international multi-sports events can we further enhance China's international competitiveness in competitive sports.

\section{Acknowledgement}

This research has been sponsored by Qing Lan Project.

\section{References}

[1] Craig. E. Wills, “The competitiveness of games in professional sports leagues,” Journal of Sports Analytics, vol. 3, no.2,pp.103-117,2017,DOI:10.3233/JSA-160122.

[2] Y.C. Zhao, “China's Disabled Population Exceeds 85 Million,” Disabilities in China, 2012, vol. 04, pp. 20.

[3] http://www.gov.cn/jrzg/2011-05/17/content_1865690.htm

[4] Y.L. Song, H.M. Huang, ect, "Analysis of Home Advantages in the Winter Olympic Games and Prospects for the 24th Winter Olympic Games in China," Sports Culture Guide, vol. 3, no. 165, pp. 89-93, 2016.

[5] BUUD H. KONING, "Sport and measurement of competition," De Economist, vol. 157, pp. 229-249, 2009, DOI:10.1007/s10645-009-9113-X.

[6] Y. Zuo, "General Administration of Sport: The Value Added in the Sports Industry Accounts for $0.7 \%$ of GDP in 2015,’[DB/OL]. http:// www.sports.qq.con/a/20151223/054767.htm, 2015.12.23/2016.2.25.

[7] National Bureau of Statistics, "2008 Statistical Bulletin on National Sports and Social Development in 2008,’[EB\OL] http//: www. gov.cn/test/2009-02/26/content_1249960.htm

[8] L.Huang, "A Comparative Study on the Structural Characteristics of Chinese and American Olympic Strategies," Sports Research and Education, vol. 31, no. 2, pp. 80-87, 2016.

[9] L. Huang, "Reform of Governance in International Sports Organizations and Lessons for China," Guangzhou: World Publishing Corporation, pp. 224, 2016.

ISSN: 0010-8189 